\title{
Genetic Aspects of Inflammation and Immune Response in Stroke
}

\author{
Dejan Nikolic ${ }^{1,2, *}$, Milena Jankovic ${ }^{3}$, Bojana Petrovic ${ }^{4}$ and Ivana Novakovic ${ }^{1}$ \\ 1 Faculty of Medicine, University of Belgrade, 11000 Belgrade, Serbia; ivana.novakovic@med.bg.ac.rs \\ 2 Physical Medicine and Rehabilitation Department, University Children's Hospital, 11000 Belgrade, Serbia \\ 3 Neurology Clinic, Clinical Center of Serbia, 11000 Belgrade, Serbia; milena.jankovic.82@gmail.com \\ 4 Clinic for Gynecology and Obstetrics, Clinical Center of Serbia, 11000 Belgrade, Serbia; \\ bojana.petrovic1977@gmail.com \\ * Correspondence: denikol27@gmail.com
}

Received: 13 September 2020; Accepted: 5 October 2020; Published: 8 October 2020

\begin{abstract}
Genetic determinants play important role in the complex processes of inflammation and immune response in stroke and could be studied in different ways. Inflammation and immunomodulation are associated with repair processes in ischemic stroke, and together with the concept of preconditioning are promising modes of stroke treatment. One of the important aspects to be considered in the recovery of patients after the stroke is a genetic predisposition, which has been studied extensively. Polymorphisms in a number of candidate genes, such as IL-6, BDNF, COX2, CYPC19, and GPIIIa could be associated with stroke outcome and recovery. Recent GWAS studies pointed to the variant in genes PATJ and $L O C$ as new genetic markers of long term outcome. Epigenetic regulation of immune response in stroke is also important, with mechanisms of histone modifications, DNA methylation, and activity of non-coding RNAs. These complex processes are changing from acute phase over the repair to establishing homeostasis or to provoke exaggerated reaction and death. Pharmacogenetics and pharmacogenomics of stroke cures might also be evaluated in the context of immuno-inflammation and brain plasticity. Potential novel genetic treatment modalities are challenged but still in the early phase of the investigation.
\end{abstract}

Keywords: genetics; inflammation; stroke; treatment; recovery

\section{Introduction}

Stroke is a complex disease with a substantial genetic component, the heritability of which ranges from $16 \%$ to $40 \%$ [1]. Around $85-90 \%$ of all stroke cases account for ischemic stroke (IS) due to an embolus or thrombosis causing vascular occlusion in situ in certain brain parts; in the rest of cases, hemorrhagic stroke (HS) occurs [2].

Cerebrovascular insult initiates a complex cascade of events at genomic, molecular, and cellular levels, and inflammation is important in this cascade, both in the Central Nervous System (CNS) and in the periphery [3]. Genetic aspects of inflammation and immune response in stroke cover several fields that will be discussed in this paper.

\section{Inflammation and Immunomodulation as Treatment Modes in Stroke}

Aside from beneficial effects of inflammation in certain conditions, when its actions are prolonged they can lead to less favorable outcomes. Systemic inflammation as well as inflammation in the brain is associated with neuronal loss in stroke patients [4]. However, besides the negative effects, inflammation might be associated with repair processes in ischemic stroke [5]. One of the important factors for both of these effects is time. Jian et al., stated that in the early stage after the stroke, microglia are recruited, while peripheral immune cells appear within one day (neutrophils even within the 
first hour) and lasting until seven days after the stroke event [6]. The CD8 ${ }^{+} \mathrm{T}$ cells appear $3 \mathrm{~h}$ after the stroke at earliest, while $\mathrm{CD} 4^{+} \mathrm{T}$ cells within $24 \mathrm{~h}$ after the stroke. The dynamics of immune cells appearance is important, having in mind especially their potential role in stroke, where neutrophils produce inflammatory factors and by the mechanisms of phagocytosis might promote tissue healing, while $\mathrm{CD} 8^{+} \mathrm{T}$ cells can be associated with the neuronal death and $\mathrm{CD} 4^{+} \mathrm{T}$ cells might play the role in tissue repair [6]. In the mice model, depletion of cytotoxic $\mathrm{T}$ lymphocytes had favorable effects on infarct volumes and behavioral deficits [7]. Moreover, the subpopulation of T cells or regulatory $\mathrm{T}$ cells (Treg) are endogenous modulators with potential neuroprotective effects, where the anti-inflammatory cytokine IL-10 plays important role in their function by augmenting Treg's or their downstream signaling pathways $[6,8]$. They appear a few days after the stroke and persisting more than 30 days [9]. The specific phenotypes of microglia or macrophages are also important when assessing post stroke tissue damage, where the M1 population is considered to be predominantly destructive, while the M2 population neuroprotective [10]. Schuhmann et al., in their study stressed that the B cells in the acute phase of the induced stroke in animal models do not influence on lesion volume and functional outcome [11].

During the acute phase that can last from minutes to hours [12], damaged brain cells can stimulate systemic immunity by releasing the specific signals that could lead to the immunodepression, thus increasing the risk of potential infections [13]. Additionally in this stage, there is the process of the promotion of adherence and transendothelial transfer of leukocytes [12]. Further, in the subacute phase the production of matrix metalloproteinases (MMP) is noticed, leading to the numerous unfavorable effects, including disruption of the blood-brain barrier, brain edema, and neuronal death [12]. In the chronic phase, adaptive immune response affecting the brain might increase the possibility of poststroke morbidity [13]. It was shown that in mice with induced cerebral ischemia there is an increased risk of infections, particularly pneumonia [9].

Additionally, patients with stroke also have a certain degree of immunosuppression that could have neuroprotective effects via cytokines and growth factors [5]. In the study of Li et al., it was noticed that for patients with acute ischemic stroke, serum cytokines are associated with stroke severity and cerebral infarct volume, particularly with IL-5 as an independent protective factor for prognosis [14]. Protective effects of $I L-4$ on animal models probably by reduced inflammation were addressed in the study of Xiong et al. [15]. Furthermore, promising results were noticed with antagonist IL-1ra in the treatment of acute ischemic stroke, where patients had a greater reduction in NIH stroke scale scores versus those who were administered a placebo for at least 3 months after the treatment [16].

In summary, it can be postulated that by controlling the inflammation and immune responses, the brain tissue damage might be controlled to a certain degree as well, along with potential improvements in stroke outcome. Therefore, large and well-designed clinical trials with standardized methods are needed in future research.

\section{Preconditioning in Stroke}

The phenomenon of preconditioning or ischemic tolerance was described in several previous studies [17-19]. In the study of Anrather et al., authors pointed that this phenomenon might alter the tolerance of the entire organism to a more lethal stimulus by previously applying stressful but sublethal stimulus probably by a cascade of molecular and biochemical events [19]. Two types of tolerances were proposed and described: the rapid tolerance lasting for a few hours and delayed tolerance probably associated with the new gene expression along with de novo protein synthesis [20]. The neuroprotective effects of preconditioning might be explained by a complex cascade of signaling events that are leading to new protein synthesis, a process proposed as a genomic reprogramming model [20]. Additionally, the increase of intragenic methylation is described in a model of preconditioning ischemia [21]. Moreover, mitochondrial roles in preconditioning were studied as well. Particularly, protective effects of the integrity of mitochondrial oxidative phosphorylation, and preserving mitochondrial function in tested subjects with cerebral ischemia, were seen for delayed preconditioning [22]. Therefore, 
the preconditioning as a phenomenon with protective effects in stroke sufferers might be considered in the future as one of the promising potential treatment modes.

From an evolutionary point of view, stroke is affecting the two most important systems for survival (nervous and immune), it's usually happening after the reproduction phase and it's not compatible with life in the wilderness [23]. Having that in mind, it is possible that the immune system is overreacting and not trying to establish homeostasis. As previously mentioned, the preconditioning immune system could "learn" that the living after a stroke is possible and to react in more helpful manner [20]. Another approach is the development of therapies for balancing immune reaction, more precisely, shifting microglial activity from pro-inflammatory and neurotoxic to anti-inflammatory and neuroprotective.

\section{Genetics and Inflammation in Post Stroke Recovery}

The importance of recovery in the post-stroke period increased in recent years especially with the advancement of medicine, science, and technology. The major burden in stroke survivors is a disability that affects various dimensions of daily living and quality of life. This disability is presented with wide variability among individuals in post-stroke period. Early diagnostics with adequate triage and implementation of innovative treatment protocols are considered to be very important in early recognition and controlling the progress and dynamics of tissue damage in affected areas of the brain [24-27]. Once the disability is present, post-stroke survivors are included in rehabilitation treatment for optimal functional improvements and prevention of further functional decline [28,29]. Nowadays, special consideration is given to promising interventions including virtual reality in the rehabilitation and telerehabilitation of stroke affected patients [30-32]. Furthermore, patient-tailored treatment along with personalized management in the post-stroke period will hopefully bring to better health care and quality of life for these patients.

One of the important aspects to be considered in the recovery of patients after the stroke is a genetic predisposition as well as potential novel genetic treatment modalities. Genetics of Ischaemic Stroke Functional Outcome Network (GISCOME) was established for identification of potential genetic loci that might influence the functional outcomes in stroke survivors [33]. So far it was pointed that genetic factors could be associated with long-term stroke outcomes, thus further genetic analyses might bring new insights for better understanding of molecular mechanisms regarding the stroke outcome [1]. Considering the acute and subacute stroke outcomes, the early neurological deterioration is found potentially to be multifactorial, with different single nucleotide polymorphisms (SNPs) that are independently associated with such condition $[1,34,35]$.

In the meta-analysis of Math et al., it was noticed that variants of BDNF and CYP2C19 genes are negatively associated with the recovery of patients after ischemic stroke, while the APOE4 gene was shown to be negatively associated with recovery of intracerebral hemorrhage [36]. Furthermore, these authors pointed that some genes involved with the drug metabolism including COX2, MRD1 as well as CYP2C19, possibly by inflammatory cascade, might have certain roles in the recovery after acute ischemic stroke [36]. The study of Maguire et al., demonstrated as well that 2 COX2 variants (rs20417 and rs5275), as well as GPIIIa variant (rs5918), are associated with functional outcomes in stroke survivors [37].

Previous reports addressed that immune response and inflammation are important factors that are associated with stroke pathogenesis and its outcome [19,38]. Even though inflammation starts locally, its mediators are disseminated inducing systemic inflammatory response [19]. The released proinflammatory mediators by vascular endothelium and brain parenchyma might locally increase the injury of the affected tissue in a stroke event. Chakraborty et al., conducted the study on genetic analyses of $I L-6$ gene promoter polymorphism and stated that a GC genotype in the study group who suffered a stroke had significantly higher levels of $I L-6$ versus those of CC and GG genotypes. Furthermore, the group with GC genotype was shown to have poorer short-term as well as a long-term outcome [39]. Increased levels of $I L-6$ were previously described in patients with acute ischemic stroke. This pro-inflammatory cytokine could induce excessive inflammatory response affecting the injury 
pathogenesis in stroke patients leading to a less favorable outcome [38]. The correlation of $I L-6$ and stroke outcome was shown in the study of Aref et al., where it was stated that the worse outcome 3 months post-stroke event was in subjects with higher levels of $I L-6$ [40]. Additionally, the recurrence of stroke was also associated with higher levels of IL-6 [40].

Several genome-wide association studies (GWAS) have found genes associated with stroke risk and results have been confirmed in independent studies [41,42]. However, GWAS studies performed to find genetic variables associated with stroke outcomes are not so frequent. Recently, about long-term stroke outcome, two GWAS studies have been published with remarkable results. The GODS (Genetic contribution to functional Outcome and Disability after Stroke) study detected that PATJ (Pals1-associated tight junction) low-frequency variants were associated with worse IS functional outcome [43]. In the GISCOME study, with more than 6000 participants, it was showen that intronic variant rs1842681 in LOC105372028 had a significant association with functional outcomes 60-90 days after stroke [44]. It is important to emphasize that the LOC gene is involved in the expression of protein phosphatase 1, which is implicated in brain plasticity. Several other variants, some within or near genes that have been linked to outcomes in animal models of stroke, also had a suggestive association with patient outcomes, but under the range of significance [44]. These studies are beginning to clarify the influence of genetics on patient recovery, which can help us to understand all the mechanisms involved.

\section{Epigenetic Regulation of Immune Response in Stroke}

Completely simplified, we can consider stroke as an acute and devastating vascular insult, causing oxygen-glucose deprivation (OGD) and leaving high-energy-demanding brain cells in metabolic stress. Such dramatic consequences require: (1) prompt response from local immune cells, (2) information spreading to other parts of the brain and the whole organism and (3) reactions in order to recover and, if possible, to re-establish homeostasis. The fastest way to change the modality of cell metabolism and signaling is trough epigenetic modifications on transcriptional and post-the transcriptional levels. Epigenetic traits are defined as heritable changes in gene expression emerging from interactions between the environment and the genome, although without alterations in the DNA sequence [45]. The most prominent epigenetic mechanisms that have been addressed in human and animal studies of immune response and stroke are histone modifications (acetylation, methylation, etc.), DNA methylation and non-coding RNAs gene expression regulation.

\subsection{Histone Modifications}

Post-translational, reversible, and extremely sensitive modifications of histones, are affecting DNA wrapping around histones in nucleosome formation and chromatin packing and organization [46]. Histone acetylation/deacetylation is regulated by two groups of enzymes (histone acetyltransferases (HATs) and histone deacetylases (HDACs)) and generally increases or inhibits transcriptional activation, respectively [47]. It has been widely reported that stroke is provoking histone deacetylation and that HDAC inhibitors are usefully reducing the process. Those inhibitors also suppressed the expression of proinflammatory proteins and connected drugs administration with changes in microglia in animal models of stroke [48]. Valproic acid is reducing inflammation, disruption of the blood-brain barrier (BBB), and improving outcome trough HDAC inhibition in rat models of hemorrhage or ischemic stroke [49-51]. Recent studies demonstrated that inhibition of HDAC with sodium butyrate is upregulating expression of anti-inflammatory mediators IL-10 and STAT3, and suppressing the expression of pro-inflammatory mediators, TNF- $\alpha$ and NOS2, IL-1 and IL-18 [52,53]. Additionally these results suggested the biphasic effect of sodium butyrate, initially suppressing inflammation by reduction of BBB permeability, and later, promoting recovery by elevation of IGF-1 expression in peripheral tissues [52]. Methylation is another form of histone modification, catalyzed by histone methyltransferases (HMTs) [54]. Its role is complex and may differentially affect gene expression, depending on temporal and spatial changes on the tissue level. Studies of animal and in vitro models of stroke demonstrated that histone methylation is affecting stroke severity during aging [55] and 
neuronal resistance in a model of hypoxic metabolic stress [56]. Besides that, studies implicated the connection of histone methylation with proinflammatory cytokines [57].

\subsection{DNA Methylation}

DNA methylation is defined as the attachment of methyl $(\mathrm{CH} 3)$ group to a $5^{\prime}$ position of the cytosine ring. The formation of 5-methylcytosine (5-mC) does not affect all cytosine residues in the DNA, rather only palindromic sites, named CpG islands. Those sites are usually located near or in promoter regions allowing the family of enzymes, DNA methyltransferases (DNMTs), to regulate gene function trough methylation process [58]. DNA methylation is preventing transcription factors binding, and, in most cases, decreasing transcription, but depending on tissue microenvironment and position in the genome, it can also promote gene expression [59]. Beside the methylation of promoter regions, alteration in gene body methylation is recognized as regulatory mechanism of gene expression and recent study confirmed that DNA methylation of exons is involved in alternative splicing [60]. Recent evidence also shed light on interaction between allele-specific DNA methylation (ASM), allele-specific binding of transcription factors (ABTF), genetic variants and environmental factors, and their role in disease risk [61]. This is extremely important for better understanding pathogenic mechanisms in multifactor diseases such as stroke.

As one of the most intensively studied epigenetic mechanisms, through a combination of genome wide association studies and a single-cell approach, DNA methylation is established as stable, but dynamic and reversible [59] and in the context of the immune system a very useful mechanism [62]. Early studies on DNMT-deficient mice models have shown an association between general suppression of DNA methylation and resistance to stroke, or covertly that DNA methylation contributes to large tissue damage even after mild ischemic brain injury [63]. Recent studies demonstrated alterations in methylation patterns trough different stages of immune reaction cascade during and after stroke. Gallego-Fabrega et al. analyzed almost 500000 DNA methylation sites in patients treated with antiplatelet drugs (aspirin or clopidogrel). They have revealed the involvement of hypomethylation of 2 "inflammation control" genes: protein phosphatase 1A (PPM1A) and TNF receptor-associated factor 3 (TRAF3) with increased stroke recurrence [64,65]. In later phases of the immune response, hypermethylated promoter of thrombospondin-1 (THBS1), a gene associated with angiogenesis and neuroprotection, decreases stroke recovery $[66,67]$.

\subsection{Non-Coding RNAs}

Non-coding RNAs are a wide group of regulatory RNAs that are not translated into proteins. Most extensively studied are microRNAs (miRs) and long non-coding RNAs (LncRNAs). MiRs are evolutionarily conserved oligonucleotides with less than 200 nucleotides in length (usually about 20) which are complementary to $3^{\prime}$-UTR of different messenger RNAs (mRNAs). Pairing miR with targeted mRNA is inhibiting translation and leading to mRNA degradation [68]. During the past decade, the role of miRs has been widely addressed in the regulation of stroke consequences, particularly in activation of microglia and the affection of numerous pro- and anti-inflammatory factors following stroke [69]. MiRs are recognized as potential novel therapeutic targets in stroke, but their expression is highly tissue or disease state-dependent. LncRNAs are consisted of more than 200 nucleotides, although, less abundant compared to miRs they show more microenvironment-dependent function [70] and have regulatory roles in a variety of metabolic processes in the nucleus and cytoplasm [71]. In recent years, the function of different lncRNAs in expression regulation after stroke is studied more extensively, especially in inflammation [72-74]. Interestingly, lncRNA may regulate the expression of genes coding for miRs. The negative correlation of nuclear enriched abundant transcript 1 (NEAT1) IncRNA has been shown in stroke prognosis and recovery with miR-124 and miR-125a, which are identified as inflammatory miRs [75].

It would be important to mention that complex epigenetic regulation of immune response in stroke is changing from the acute phase (inflammation), over repair phase to establishing homeostasis, or to 
provoke exaggerated reaction and death [76]. Contribution to complexity gives spatial distribution of different processes in stroke core, penumbra or unaffected tissues with numerous, overlapping regulatory layers (Figure 1). An increasing number of studies will contribute to more detailed maps of the epigenomic landscape, but its dynamic signature is complicating attempts to define useful biomarkers and predict the outcome of prevention measures and potential therapies.

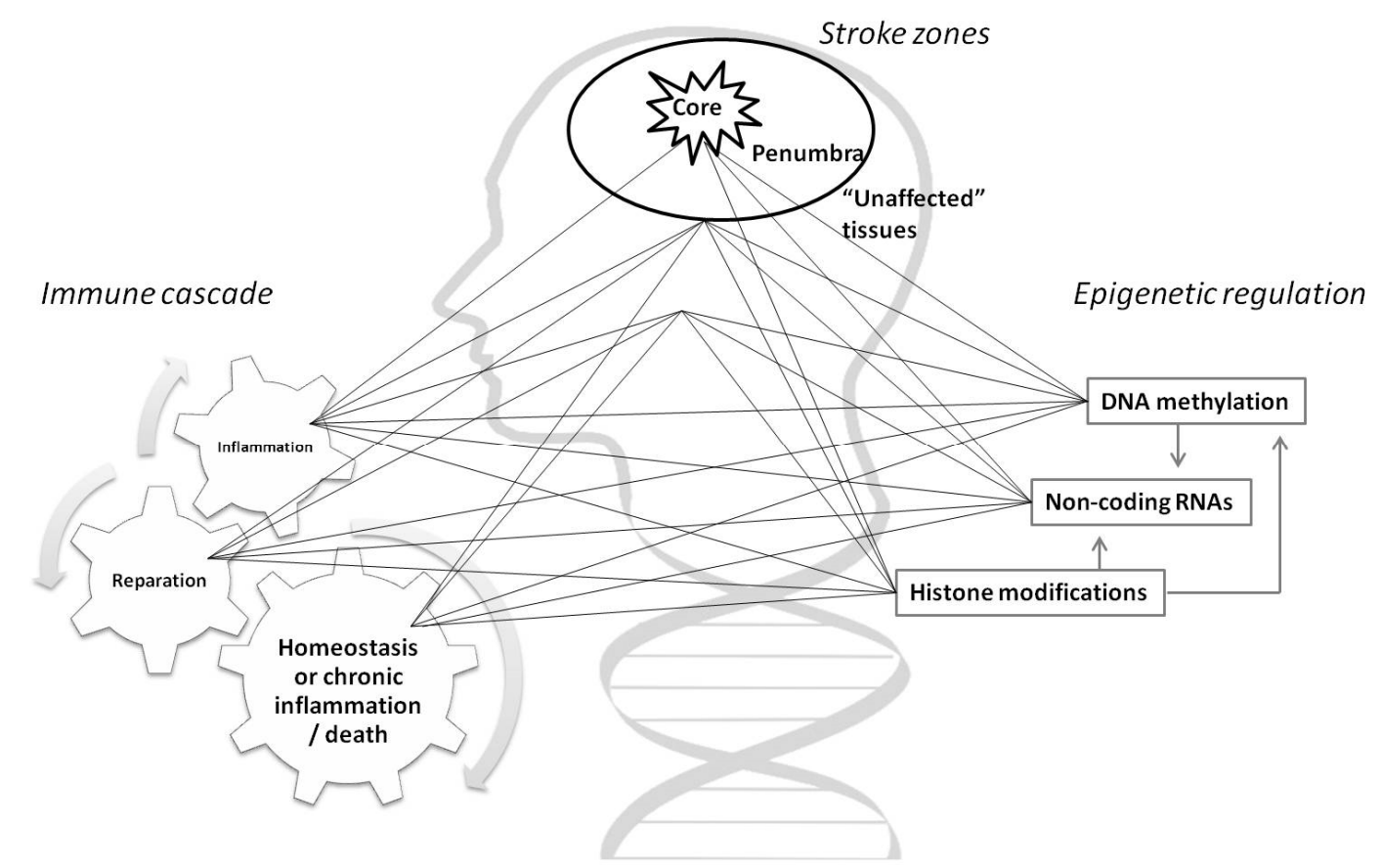

Figure 1. Spatio-temporal pattern of epigenetic regulation in immune response in stroke. The scheme is highlighting multidimensional relations of the immune system and epigenetic mechanisms in different stroke zones over time. Stroke is unequally affecting brain tissues, with irreversible neuronal damage in stroke core and metabolic changes with the possibility counteract tissue injury in the penumbra area. Additionally, stroke is provoking immune response leading to inflammation and starting an immune cascade with consequences not only in the brain but also in the whole organism. Alteration of immune function is conducted through complex epigenetic regulation which is sensitive to temporal changes in the tissue microenvironment.

\section{Pharmacogenetic Markers in Stroke}

The ability of a brain to repair after a stroke depends on certain factors. Therapeutic options in stroke are turned towards the regeneration of a brain cell network taking into account neuroplasticity. Despite pharmaceutical efforts to help this process, pharmacogenomics gave evidence about resistance to stroke therapy due to individual variability in response to the drug.

In IS, nerve cells in the central zone of ischemia cannot be saved. However, in the surrounding penumbra neurons are functionally disturbed, but structurally intact, with the possibility for the recovery of their function. Without timely recanalization, an irreversible structural and functional damage in the zone of penumbra will occur with a significant effect on neurological damage and disability level [77]. The therapy of choice in the acute phase of IS is an intravenous administration of recombined tissue plasminogen activator (rt-PA). However, this therapy can cause potentially serious side effects, mostly hemorrhagic complications and the administration criteria are strictly defined having in mind inter-patient variability [78]. Pharmacogenetic investigations in this field are at the beginning, with available results from only several studies. The strong candidate gene in such studies is PAI-1 (plasminogen activator inhibitor 1). The product of the PAI-1 gene binds to $\mathrm{t}-\mathrm{PA}$, forming an inactive complex and acting as an inhibitor of endogenous fibrinolytic activity [79]. According to the literature data, only a few studies considered the association between PAI-1 4G/5G 
gene polymorphism and rtPA efficacy, with conflicting results. Fernandez-Cadenas revealed that the $4 \mathrm{G} / 4 \mathrm{G}$ genotype may be responsible for the poorer recovery of patients with IS treated with rtPA [80]. A recent study by Dusanovic Pjevic et al. could not confirm the impact of $4 \mathrm{G} / 5 \mathrm{G}$ polymorphism on patient's recovery evaluated by the modified Rankin scale (mRS), nor its influence on the rate of hemorrhagic transformation (HT) [81]. Another candidate gene is ACE (angiotensin-converting enzyme) because $A C E$, beside the vasoconstrictive effects, has a role in fibrinolysis suppression. However, the importance of $A C E$ I/D gene polymorphism in pharmacogenetics of rt-PA and stroke outcome is still controversial [81].

Antiplatelet drugs are widely used in stroke therapy and prevention so their pharmacogenetics and pharmacogenomics are extensively analyzed. Studies revealed single nucleotide polymorphisms (SNPs) of cytochrome P450 (CYP) enzymes and their interactions affect biotransformation of antiplatelet drug Clopidogrel, inducing resistance to therapy in acute ischemic stroke $[82,83]$. Genetic variants and specific gene-gene interactions among cyclooxygenase-2 (COX-2), platelet membrane receptor P2Y1 and glycoprotein GPIIIa are associated with aspirin resistance. Interestingly enough, the same gene variants could be associated with early neurological deterioration, as it is described above [32]. Oral anticoagulant therapy also showed clear pharmacogenetic markers responsible for interindividual dosage variability and linked to the risk of bleeding as an adverse effect. Studies confirmed that CYP2C9 and VKORC1 (vitamin K epoxide reductase complex, subunit 1) gene variants constitute strong risk factors of warfarin-related intracerebral hemorrhage. In addition, there are data about the role of both $\varepsilon 2$ and $\varepsilon 4$ variants in the $A P O E$ gene as risk alleles. [84-86].

The novel epigenetic and sequencing studies should be designed to examine the pharmacogenetics of the drug resistance in stroke, as the essential part of personalized medicine.

\section{Gene Therapy for Stroke}

One of the main scientific efforts in the field of stroke gene therapy is to genetically reprogram cells in order to reduce the inflammatory response and to initiate regeneration of damaged tissue during stroke recovery. A new gene therapy turns glial cells into neurons, repairing the damage that results from stroke and significantly improving motor function in rodents.

Zeng et al. showed that the tripartite motif containing 9 (TRIM9), a brain-specific ubiquitin ligase, is a potent inhibitor of a nuclear factor kappa (NF- $\mathrm{kB}$ ) signaling pathway in cell culture in vitro (upon cytokine stimulation). In murine stroke models, systemic administration of a recombinant adeno-associated virus that drove brain-wide TRIM9 expression effectively resolved neuroinflammation and alleviated neuronal death (especially in aged mice). Their findings suggest that TRIM9 is essential for resolving NF-kB-dependent neuroinflammation to promote recovery and repair after brain injury and that manipulating TRIM9 expression may represent an attractive immunomodulatory therapeutic target [87].

G-CSF (granulocyte-colony stimulating factor) is an endogenous ligand in the CNS that displays several important functions including anti-apoptotic activity, immunomodulatory action, stimulates neurogenesis, and angiogenic capabilities. G-CSF treatment exerts neuroprotective effects on damaged neurons by decreasing pro-apoptotic proteins and increasing of antiapoptotic proteins, both reducing acute neuronal degeneration and adding to long-term plasticity after cerebral ischemia [88,89]. Balseanu et al., demonstrated in a stroke rat model that daily intravenous injection of G-CSF led to robust and consistent improvement of neurological functions, which in a combination with a single intravenous administration of mesenchymal stromal cells (MSC) increased the neurogenesis in the subventricular zone and improved microvessel density in the formerly infarct core and perilesional area of treated aged rats, but had no beneficial effect on the infarct volume or mortality [90]. The same group revealed that the combination of G-CSF with bone marrow-derived mononuclear cells (BM MNC) in aged rats led to the no advantage over G-CSF treatment alone, suggesting that different outcomes might be achieved depending on the type of cells used [91]. Ren et al. confirmed the neuroprotective effect of G-CSF gene therapy in rodents and suggested a translational possibility of 
this research strategy in humans by exprimation of the G-CSF gene into an adenovirus that is safe and known to infect brain cells efficiently [92].

Chen et al. identified leucine zipper-bearing kinase $L Z K$ as a critical cell-intrinsic regulator of astrocyte reactivity, and consequently post-injury recovery and repair of the mammalian CNS. Using genetic loss-of-function and gain-of-function strategies in vivo, they showed that the conserved LZK promotes astrocyte reactivity and glial scar formation after CNS injury. Induced LZK gene deletion in astrocytes of adult mice reduced astrogliosis and impaired glial scar formation, resulting in increased lesion size after spinal cord injury. Conversely, LZK overexpression in astrocytes enhanced astrogliosis and reduced lesion size. Remarkably, in the absence of injury, LZK overexpression alone induced widespread astrogliosis in the CNS and upregulated astrogliosis activators pSTAT3 and SOX9. These results enable broad translational implications for neural repair [93].

Results obtained by Sokolov et al. imply that intrathecal injection of genetically engineered umbilical cord blood mononuclear cells (UCB-MC) over-expressing therapeutic molecules vascular endothelial growth factor (VEGF), glial cell line-derived neurotrophic factor (GDNF), neural cell adhesion molecule (NCAM) might represent a novel avenue for future research into treating stroke. Remodeling of the brain cortex in the stroke area was confirmed by the reduction of infarct volume and attenuated neural cell death, depletion of astrocytes and microglial cells, and an increase in the number of oligodendroglial cells and synaptic proteins expression [94].

NeuroD1 (neurogenic differentiation 1) is a member of the NeuroD family of basic helix-loop-helix transcription factors. Chen et al. were reported regeneration of one third of the total lost neurons after ischemic injury and simultaneously protection of another one third of injured neurons, leading to a significant neuronal recovery, using NeuroD1 adeno-associated virus (AAV)-based gene therapy. They demonstrate that in vivo astrocyte-to-neuron conversion mediated through such gene therapy can efficiently regenerate a large number of functional neurons in an ischemic injury model and achieve the functional rescue of both motor and cognitive deficits in rodent animals [95].

Although the effectiveness of gene therapy for stroke is shown only in ischemic stroke animal models, results are highly encouraging and could make a real difference in the future.

\section{Aging and Inflammation in Stroke}

The impact of aging on immune response in stroke patients is of great importance, since majority of them belong to the group of people above 65 years [96,97]. Previously it was stated that the aging, as a non-modifiable risk factor, have a negative impact on the immune response [96]. The studies on animal models revealed that aged mice have reduced infarct volumes but worse functional outcomes. One of possible mechanisms that might explain to the certain degree increased mortality in aged animals after the stroke is a profound splenic contraction affecting peripheral immunosuppression [97]. Additionally, ageing is associated with the decreased brain plasticity, where in aged rats there is a delay of plasticity-associated proteins expression in affected region of the stroke [98]. Popa-Wagner et al., stated that aged animal models have rapid formation of glial scars after the stroke. Such phenomenon might be explained by the premature cellular proliferation, with potential role of nestin positive cells that arise from the capillary wall [99]. Furthermore, it was suggested that nestin, which is neuroepithelial marker, could facilitate cellular structural remodeling after the stroke [100]. Moreover, increased low-grade chronic inflammation is associated with an aging [101]. Further, it can be postulated that in aged individuals presence of chronic systemic inflammation prior to the stroke event could create a "primed" inflammatory environment that might lead to the exacerbation of the post-stroke inflammation response [102]. Therefore, reduced functional recovery potential in aged animal models after the stroke could be associated by the dysregulation in timing and intensity of cellular and genetic responses to the injured tissue $[99,103]$.

Aged individuals activate most growth-promoting genes at later time-points following stroke than young adults [103]. In experimental models, inflammatory response of aging brain to ischemia-reperfusion injury is characterized by increased chemokine expression, cytokine expression including TNF- $\alpha$, IL-1, IL- 6 
and increased cell death. At transcriptional level, five inflammation-related genes in the penumbra region (Protein tyrosine phosphatase receptor type C-Ptprc, Prostaglandin E synthase 3-Ptges3, transforming growth factor, beta receptor I-Tgfbr1, IL-6, ribosomal protein S2-Rps2) were found up-regulated in aged rats but not in young animals [102]. Regarding testing of new therapeutic options, Popa-Wagner's group showed the specific response of a aged animals with stroke, as it is previously discussed $[90,91]$.

\section{Conclusions}

In the conclusion, studying of genetic aspects of inflammation and immune response in stroke is very dynamic and versatile, and opens numerous options for crosstalk between the basic science and a clinical applications in stroke management and treatment.

Author Contributions: D.N.; M.J. and B.P.; Reviewed concept and design, critical revision of the manuscript for important intellectual content; I.N.; critical revision of the manuscript for important intellectual content, study supervision. All authors have read and agreed to the final version of the manuscript.

Funding: The Review was Supported by Serbian Ministry of Education, Science and Technological Development, Contract No. 200110.

Conflicts of Interest: The authors declare no conflict of interest.

\section{References}

1. Torres-Aguila, N.P.; Carrera, C.; Muiño, E.; Cullell, N.; Cárcel-Márquez, J.; Gallego-Fabrega, C.; González-Sánchez, J.; Bustamante, A.; Delgado, P.; Ibañez, L.; et al. Acute Endophenotypes Group of the International Stroke Genetics Consortium (ISGC). Clinical Variables and Genetic Risk Factors Associated with the Acute Outcome of Ischemic Stroke: A Systematic Review. J. Stroke 2019, 21, 276-289. [CrossRef]

2. Sacco, R.L.; Kasner, S.E.; Broderick, J.P.; Caplan, L.R.; Connors, J.J.; Culebras, A.; Elkind, M.S.; George, M.G.; Hamdan, A.D.; Higashida, R.T.; et al. An updated definition of stroke for the 21st century: A statement for healthcare professionals from the American Heart Association/American Stroke Association. Stroke 2013, 44, 2064-2089. [CrossRef] [PubMed]

3. Tuttolomondo, A.; Di Raimondo, D.; Pecoraro, R.; Arnao, V.; Pinto, A.; Licata, G. Inflammation in Ischemic Stroke Subtypes. Curr. Pharm. Des. 2012, 18, 4289-4310. [CrossRef] [PubMed]

4. Cuenca-López, M.D.; Brea, D.; Segura, T.; Galindo, M.F.; Antón-Martínez, D.; Agulla, J.; Castillo, J.; Jordán, J. La inflamación como agente terapéutico en el infarto cerebral: Respuesta inflamatoria celular y mediadores inflamatorios [Inflammation as a therapeutic agent in cerebral infarction: Cellular inflammatory response and inflammatory mediators]. Rev. Neurol. 2010, 50, 349-359. [PubMed]

5. McCombe, P.A.; Read, S.J. Immune and inflammatory responses to stroke: Good or bad? Int. J. Stroke 2008, 3, 254-265. [CrossRef] [PubMed]

6. Jian, Z.; Liu, R.; Zhu, X.; Smerin, D.; Zhong, Y.; Gu, L.; Fang, W.; Xiong, X. The Involvement and Therapy Target of Immune Cells After Ischemic Stroke. Front. Immunol. 2019, 10, 2167. [CrossRef]

7. Mracsko, E.; Liesz, A.; Stojanovic, A.; Lou, W.P.; Osswald, M.; Zhou, W.; Karcher, S.; Winkler, F.; Martin-Villalba, A.; Cerwenka, A.; et al. Antigen dependently activated cluster of differentiation 8-positive $\mathrm{T}$ cells cause perforin-mediated neurotoxicity in experimental stroke. J. Neurosci. 2014, 34, 16784-16795. [CrossRef]

8. Liesz, A.; Zhou, W.; Na, S.Y.; Hämmerling, G.J.; Garbi, N.; Karcher, S.; Mracsko, E.; Backs, J.; Rivest, S.; Veltkamp, R. Boosting regulatory T cells limits neuroinflammation in permanent cortical stroke. J. Neurosci. 2013, 33, 17350-173562. [CrossRef]

9. Qin, X.; Akter, F.; Qin, L.; Cheng, J.; Guo, M.; Yao, S.; Jian, Z.; Liu, R.; Wu, S. Adaptive Immunity Regulation and Cerebral Ischemia. Front. Immunol. 2020, 11, 689. [CrossRef]

10. Xiong, X.Y.; Liu, L.; Yang, Q.W. Functions and mechanisms of microglia/macrophages in neuroinflammation and neurogenesis after stroke. Prog. Neurobiol. 2016, 142, 23-44. [CrossRef]

11. Schuhmann, M.K.; Langhauser, F.; Kraft, P.; Kleinschnitz, C. B cells do not have a major pathophysiologic role in acute ischemic stroke in mice. J. Neuroinflamm. 2017, 14, 112. [CrossRef] [PubMed]

12. Jayaraj, R.L.; Azimullah, S.; Beiram, R.; Jalal, F.Y.; Rosenberg, G.A. Neuroinflammation: Friend and foe for ischemic stroke. J. Neuroinflamm. 2019, 16, 142. [CrossRef] [PubMed] 
13. Iadecola, C.; Buckwalter, M.S.; Anrather, J. Immune responses to stroke: Mechanisms, modulation, and therapeutic potential. J. Clin. Investig. 2020, 130, 2777-2788. [CrossRef] [PubMed]

14. Li, X.; Lin, S.; Chen, X.; Huang, W.; Li, Q.; Zhang, H.; Chen, X.; Yang, S.; Jin, K.; Shao, B. The Prognostic Value of Serum Cytokines in Patients with Acute Ischemic Stroke. Aging Dis. 2019, 10, 544-556. [CrossRef]

15. Xiong, X.; Barreto, G.E.; Xu, L.; Ouyang, Y.B.; Xie, X.; Giffard, R.G. Increased brain injury and worsened neurological outcome in interleukin-4 knockout mice after transient focal cerebral ischemia. Stroke 2011, 42, 2026-2032. [CrossRef]

16. Fu, Y.; Liu, Q.; Anrather, J.; Shi, F.D. Immune interventions in stroke. Nat. Rev. Neurol. 2015, 11, 524-535. [CrossRef]

17. Kitagawa, K.; Matsumoto, M.; Tagaya, M.; Hata, R.; Ueda, H.; Niinobe, M.; Handa, N.; Fukunaga, R.; Kimura, K.; Mikoshiba, K. 'Ischemic tolerance' phenomenon found in the brain. Brain Res. 1990, 528, 21-24. [CrossRef]

18. Przyklenk, K.; Bauer, B.; Ovize, M.; Kloner, R.A.; Whittaker, P. Regional ischemic 'preconditioning' protects remote virgin myocardium from subsequent sustained coronary occlusion. Circulation 1993, 87, 893-899. [CrossRef]

19. Anrather, J.; Iadecola, C. Inflammation and Stroke: An Overview. Neurotherapeutics 2016, 13, 661-670. [CrossRef]

20. Stenzel-Poore, M.P.; Stevens, S.L.; King, J.S.; Simon, R.P. Preconditioning reprograms the response to ischemic injury and primes the emergence of unique endogenous neuroprotective phenotypes: A speculative synthesis. Stroke 2007, 38 (Suppl. S2), 680-685. [CrossRef]

21. Meller, R.; Pearson, A.; Simon, R.P. Dynamic changes in DNA methylation in ischemic tolerance. Front. Neurol. 2015, 6, 102. [CrossRef] [PubMed]

22. Dirnagl, U.; Meisel, A. Endogenous neuroprotection: Mitochondria as gateways to cerebral preconditioning? Neuropharmacology 2008, 55, 334-344. [CrossRef] [PubMed]

23. Duris, K.; Jurajda, M. Evolutionary concept of inflammatory response and stroke. J. Neurosci. Res. 2020, 98, 98-104. [CrossRef] [PubMed]

24. Murray, N.M.; Unberath, M.; Hager, G.D.; Hui, F.K. Artificial intelligence to diagnose ischemic stroke and identify large vessel occlusions: A systematic review. J. Neurointerv. Surg. 2020, 12, 156-164. [CrossRef]

25. Yew, K.S.; Cheng, E. Acute stroke diagnosis. Am. Fam. Phys. 2009, 80, 33-40.

26. Suh, C.H.; Jung, S.C.; Kim, B.; Cho, S.J.; Woo, D.C.; Oh, W.Y.; Lee, J.G.; Kim, K.W. Neuroimaging in Randomized, Multi-Center Clinical Trials of Endovascular Treatment for Acute Ischemic Stroke: A Systematic Review. Korean J. Radiol. 2020, 21, 42-57. [CrossRef]

27. Badhiwala, J.H.; Nassiri, F.; Alhazzani, W.; Selim, M.H.; Farrokhyar, F.; Spears, J.; Kulkarni, A.V.; Singh, S.; Alqahtani, A.; Rochwerg, B.; et al. Endovascular Thrombectomy for Acute Ischemic Stroke: A Meta-analysis. JAMA 2015, 314, 1832-1843. [CrossRef]

28. Dobkin, B.H.; Dorsch, A. New evidence for therapies in stroke rehabilitation. Curr. Atheroscler. Rep. 2013, 15, 331. [CrossRef]

29. Hu, Y.; Zhong, D.; Xiao, Q.; Chen, Q.; Li, J.; Jin, R. Kinesio Taping for Balance Function after Stroke: A Systematic Review and Meta-Analysis. Evid. Based Complement. Alternat. Med. 2019, 2019, 8470235. [CrossRef]

30. Iruthayarajah, J.; McIntyre, A.; Cotoi, A.; Macaluso, S.; Teasell, R. The use of virtual reality for balance among individuals with chronic stroke: A systematic review and meta-analysis. Top. Stroke Rehabil. 2017, 24, 68-79. [CrossRef]

31. Aramaki, A.L.; Sampaio, R.F.; Reis, A.C.S.; Cavalcanti, A.; Dutra, F.C.M.S.E. Virtual reality in the rehabilitation of patients with stroke: An integrative review. Arquivos Neuropsiquiatria 2019, 77, 268-278. [CrossRef] [PubMed]

32. Sarfo, F.S.; Ulasavets, U.; Opare-Sem, O.K.; Ovbiagele, B. Tele-Rehabilitation after Stroke: An Updated Systematic Review of the Literature. J. Stroke Cerebrovasc. Dis. 2018, 27, 2306-2318. [CrossRef] [PubMed]

33. Maguire, J.M.; Bevan, S.; Stanne, T.M.; Lorenzen, E.; Fernandez-Cadenas, I.; Hankey, G.J.; Jimenez-Conde, J.; Jood, K.; Lee, J.M.; Lemmens, R.; et al. GISCOME-Genetics of Ischaemic Stroke Functional Outcome network: A protocol for an international multicentre genetic association study. Eur. Stroke J. 2017, 2, $229-237$. [CrossRef] [PubMed] 
34. Yi, X.; Wang, C.; Zhou, Q.; Lin, J. Interaction among COX-2, P2Y1 and GPIIIa gene variants is associated with aspirin resistance and early neurological deterioration in Chinese stroke patients. BMC Neurol. 2017, $17,4$. [CrossRef]

35. Yi, X.; Lin, J.; Wang, C.; Zhou, Q. CYP Genetic Variants, CYP Metabolite Levels, and Neurologic Deterioration in Acute Ischemic Stroke in Chinese Population. J. Stroke Cerebrovasc. Dis. 2017, 26, 969-978. [CrossRef]

36. Math, N.; Han, T.S.; Lubomirova, I.; Hill, R.; Bentley, P.; Sharma, P. Influences of genetic variants on stroke recovery: A meta-analysis of the 31,895 cases. Neurol. Sci. 2019, 40, 2437-2445. [CrossRef]

37. Maguire, J.; Thakkinstian, A.; Levi, C.; Lincz, L.; Bisset, L.; Sturm, J.; Scott, R.; Whyte, S.; Attia, J. Impact of COX-2 rs5275 and rs20417 and GPIIIa rs5918 polymorphisms on 90-day ischemic stroke functional outcome: A novel finding. J. Stroke Cerebrovasc. Dis. 2011, 20, 134-144. [CrossRef]

38. Jin, R.; Liu, L.; Zhang, S.; Nanda, A.; Li, G. Role of inflammation and its mediators in acute ischemic stroke. J. Cardiovasc. Transl. Res. 2013, 6, 834-851. [CrossRef]

39. Chakraborty, B.; Chowdhury, D.; Vishnoi, G.; Goswami, B.; Kishore, J.; Agarwal, S. Interleukin-6 gene -174 $\mathrm{G} / \mathrm{C}$ promoter polymorphism predicts severity and outcome in acute ischemic stroke patients from north India. J. Stroke Cerebrovasc. Dis. 2013, 22, 683-689. [CrossRef]

40. Aref, H.M.A.; Fahmy, N.A.; Khalil, S.H.; Ahmed, M.F.; ElSadek, A.; Abdulghani, M.O. Role of interleukin-6 in ischemic stroke outcome. Egypt J. Neurol. Psychiatry Neurosurg. 2020, 56, 12. [CrossRef]

41. Lindgren, A.; Maguire, J. Stroke recovery genetics. Stroke 2016, 47, 2427-2434. [CrossRef] [PubMed]

42. Malik, R.; Chauhan, G.; Traylor, M.; Sargurupremraj, M.; Okada, Y.; Mishra, A.; Rutten-Jacobs, L.; Giese, A.K.; van der Laan, S.W.; Gretarsdottir, S.; et al. Multiancestry genome-wide association study of 520,000 subjects identifies 32 loci associated with stroke and stroke subtypes. Nat. Genet. 2018, 50, 524-537. [CrossRef] [PubMed]

43. Mola-Caminal, M.; Carrera, C.; Soriano-Tárraga, C.; Giralt-Steinhauer, E.; Díaz-Navarro, R.M.; Tur, S.; Jiménez, C.; Medina-Dols, A.; Cullell, N.; Torres-Aguila, N.P.; et al. PATJ low frequency variants are associated with worse ischemic stroke functional outcome-A genome-wide meta-analysis. Circ. Res. 2019, 124, 114-120. [CrossRef] [PubMed]

44. Söderholm, M.; Pedersen, A.; Lorentzen, E.; Stanne, T.M.; Bevan, S.; Olsson, M.; Cole, J.W.; Fernandez-Cadenas, I.; Hankey, G.J.; Jimenez-Conde, J.; et al. Genome-wide association meta-analysis of functional outcome after ischemic stroke. Neurology 2019, 92, e1271-e1283. [CrossRef] [PubMed]

45. Berger, S.L.; Kouzarides, T.; Shiekhattar, R.; Shilatifard, A. An operational definition of epigenetics. Genes Dev. 2009, 23, 781-783. [CrossRef] [PubMed]

46. Margueron, R.; Reinberg, D. Chromatin structure and the inheritance of epigenetic information. Nat. Rev. Genet. 2010, 11, 285-296. [CrossRef] [PubMed]

47. Yang, X.J.; Seto, E. HATs and HDACs: From structure, function and regulation to novel strategies for therapy and prevention. Oncogene 2007, 26, 5310-5318. [CrossRef]

48. Faraco, G.; Pancani, T.; Formentini, L.; Mascagni, P.; Fossati, G.; Leoni, F.; Moroni, F.; Chiarugi, A. Pharmacological inhibition of histone deacetylases (HDACs) by suberoylanilide hydroxamic acid (SAHA) specifically alters gene expression and reduces ischemic injury in the mouse brain. Mol. Pharmacol. 2006, 70, 1876-1884. [CrossRef]

49. Sinn, D.I.; Kim, S.J.; Chu, K.; Jung, K.H.; Lee, S.T.; Song, E.C.; Kim, J.M.; Park, D.K.; Kun Lee, S.; Kim, M.; et al. Valproic acid-mediated neuroprotection in intracerebral hemorrhage via histone deacetylase inhibition and transcriptional activation. Neurobiol. Dis. 2007, 26, 464-472. [CrossRef]

50. Kim, H.J.; Rowe, M.; Ren, M.; Hong, J.S.; Chen, P.S.; Chuang, D.M. Histone deacetylase inhibitors exhibit anti-inflammatory and neuroprotective effects in a rat permanent ischemic model of stroke: Multiple mechanisms of action. J. Pharmacol. Exp. Ther. 2007, 321, 892-901. [CrossRef]

51. Wang, Z.; Leng, Y.; Tsai, L.K.; Leeds, P.; Chuang, D.M. Valproic acid attenuates blood-brain barrier disruption in a rat model of transient focal cerebral ischemia: The roles of HDAC and MMP-9 inhibition. J. Cereb. Blood Flow Metab. 2011, 31, 52-57. [CrossRef]

52. Park, M.J.; Sohrabji, F. The histone deacetylase inhibitor, sodium butyrate, exhibits neuroprotective effects for ischemic stroke in middle-aged female rats. J. Neuroinflamm. 2016, 13, 300. [CrossRef] [PubMed]

53. Patnala, R.; Arumugam, T.V.; Gupta, N.; Dheen, S.T. HDAC Inhibitor Sodium Butyrate-Mediated Epigenetic Regulation Enhances Neuroprotective Function of Microglia During Ischemic Stroke. Mol. Neurobiol. 2017, 54, 6391-6411. [CrossRef] [PubMed] 
54. Rice, J.C.; Briggs, S.D.; Ueberheide, B.; Barber, C.M.; Shabanowitz, J.; Hunt, D.F.; Shinkai, Y.; Allis, C.D. Histone methyltransferases direct different degrees of methylation to define distinct chromatin domains. Mol. Cell. 2003, 12, 1591-1598. [CrossRef]

55. Chisholm, N.C.; Henderson, M.L.; Selvamani, A.; Park, M.J.; Dindot, S.; Miranda, R.C.; Sohrabji, F. Histone methylation patterns in astrocytes are influenced by age following ischemia. Epigenetics 2015, 10, 142-152. [CrossRef] [PubMed]

56. Schweizer, S.; Harms, C.; Lerch, H.; Flynn, J.; Hecht, J.; Yildirim, F.; Meisel, A.; Märschenz, S. Inhibition of histone methyltransferases SUV39H1 and G9a leads to neuroprotection in an in vitro model of cerebral ischemia. J. Cereb. Blood Flow Metab. 2015, 35, 1640-1647. [CrossRef] [PubMed]

57. Choi, J.Y.; Yoon, S.S.; Kim, S.E.; Ahn, J.S. KDM4B histone demethylase and G9a regulate expression of vascular adhesion proteins in cerebral microvessels. Sci. Rep. 2017, 7, 45005. [CrossRef]

58. Moore, L.D.; Le, T.; Fan, G. DNA methylation and its basic function. Neuropsychopharmacology 2013, 38, 23-38. [CrossRef]

59. Luo, C.; Hajkova, P.; Ecker, J.R. Dynamic DNA methylation: In the right place at the right time. Science 2018, 361, 1336-1340. [CrossRef]

60. Shayevitch, R.; Askayo, D.; Keydar, I.; Ast, G. The importance of DNA methylation of exons on alternative splicing. RNA 2018, 24, 1351-1362. [CrossRef]

61. Wang, H.; Lou, D.; Wang, Z. Crosstalk of Genetic Variants, Allele-Specific DNA Methylation, and Environmental Factors for Complex Disease Risk. Front. Genet. 2019, 9, 695. [CrossRef] [PubMed]

62. Morales-Nebreda, L.; McLafferty, F.S.; Singer, B.D. DNA methylation as a transcriptional regulator of the immune system. Transl. Res. 2019, 204, 1-18. [CrossRef] [PubMed]

63. Endres, M.; Meisel, A.; Biniszkiewicz, D.; Namura, S.; Prass, K.; Ruscher, K.; Lipski, A.; Jaenisch, R.; Moskowitz, M.A.; Dirnagl, U. DNA methyltransferase contributes to delayed ischemic brain injury. J. Neurosci. 2000, 20, 3175-3181. [CrossRef] [PubMed]

64. Gallego-Fabrega, C.; Carrera, C.; Reny, J.L.; Fontana, P.; Slowik, A.; Pera, J.; Pezzini, A.; Serrano-Heras, G.; Segura, T.; Martí-Fàbregas, J.; et al. TRAF3 Epigenetic Regulation Is Associated with Vascular Recurrence in Patients with Ischemic Stroke. Stroke 2016, 47, 1180-1186. [CrossRef] [PubMed]

65. Gallego-Fabrega, C.; Carrera, C.; Reny, J.L.; Fontana, P.; Slowik, A.; Pera, J.; Pezzini, A.; Serrano-Heras, G.; Segura, T.; Bin Dukhyil, A.A.; et al. PPM1A Methylation Is Associated with Vascular Recurrence in Aspirin-Treated Patients. Stroke 2016, 47, 1926-1929. [CrossRef]

66. Lawler, P.R.; Lawler, J. Molecular basis for the regulation of angiogenesis by thrombospondin-1 and -2 . Cold Spring Harb. Perspect. Med. 2012, 2, a006627. [CrossRef]

67. Ng, G.Y.; Lim, Y.A.; Sobey, C.G.; Dheen, T.; Fann, D.Y.; Arumugam, T.V. Epigenetic regulation of inflammation in stroke. Ther. Adv. Neurol. Disord. 2018, 11. [CrossRef]

68. Liu, J. Control of protein synthesis and mRNA degradation by microRNAs. Curr. Opin. Cell. Biol. 2008, 20, 214-221. [CrossRef]

69. Khoshnam, S.E.; Winlow, W.; Farbood, Y.; Moghaddam, H.F.; Farzaneh, M. Emerging Roles of microRNAs in Ischemic Stroke: As Possible Therapeutic Agents. J. Stroke 2017, 19, 166-187. [CrossRef]

70. Batista, P.J.; Chang, H.Y. Long noncoding RNAs: Cellular address codes in development and disease. Cell 2013, 152, 1298-1307. [CrossRef]

71. Yu, B.; Wang, S. Angio-LncRs: LncRNAs that regulate angiogenesis and vascular disease. Theranostics 2018, 8, 3654-3675. [CrossRef] [PubMed]

72. Feng, L.; Guo, J.; Ai, F. Circulating long noncoding RNA ANRIL downregulation correlates with increased risk, higher disease severity and elevated pro-inflammatory cytokines in patients with acute ischemic stroke. J. Clin. Lab. Anal. 2019, 33, e22629. [CrossRef] [PubMed]

73. Deng, Y.; Chen, D.; Wang, L.; Gao, F.; Jin, B.; Lv, H.; Zhang, G.; Sun, X.; Liu, L.; Mo, D.; et al. Silencing of Long Noncoding RNA Nespas Aggravates Microglial Cell Death and Neuroinflammation in Ischemic Stroke. Stroke 2019, 50, 1850-1858. [CrossRef] [PubMed]

74. Kim, J.M.; Moon, J.; Yu, J.S.; Park, D.K.; Lee, S.T.; Jung, K.H.; Chu, K. Altered long noncoding RNA profile after intracerebral hemorrhage. Ann. Clin. Transl. Neurol. 2019, 6, 2014-2025. [CrossRef]

75. Li, P.; Duan, S.; Fu, A. Long noncoding RNA NEAT1 correlates with higher disease risk, worse disease condition, decreased miR-124 and miR-125a and predicts poor recurrence-free survival of acute ischemic stroke. J. Clin. Lab. Anal. 2020, 34, e23056. [CrossRef] 
76. Placek, K.; Schultze, J.L.; Aschenbrenner, A.C. Epigenetic reprogramming of immune cells in injury, repair, and resolution. J. Clin. Investig. 2019, 129, 2994-3005. [CrossRef]

77. Astrup, J. Energy-requiring cell functions in the ischemic brain. Their critical supply and possible inhibition in protective therapy. J. Neurosurg. 1982, 56, 482-497. [CrossRef]

78. Jauch, E.C.; Saver, J.L.; Adams, H.P., Jr.; Bruno, A.; Connors, J.J.; Demaerschalk, B.M.; Khatri, P.; McMullan, P.W., Jr.; Qureshi, A.I.; Rosenfield, K.; et al. Guidelines for the early management of patients with acute ischemic stroke: A guideline for healthcare professionals from the American Heart Association/American Stroke Association. Stroke 2013, 44, 870-947. [CrossRef]

79. Lijnen, H. Pleiotropic functions of plasminogen activator inhibitor-1. J. Thromb. Haemost. 2005, 3, 35-45. [CrossRef]

80. Fernandez-Cadenas, I.; Del Rio-Espinola, A.; Rubiera, M.; Mendioroz, M.; Domingues-Montanari, S.; Cuadrado, E.; Hernandez-Guillamon, M.; Rosell, A.; Ribo, M.; Alvarez-Sabin, J.; et al. PAI-1 4G/5G polymorphism is associated with brain vessel reocclusion after successful fibrinolytic therapy in ischemic stroke patients. Int. J. Neurosci. 2010, 120, 245-251. [CrossRef]

81. Dušanović Pjević, M.; Beslac Bumbaširevic, L.; Vojvodic, L.; Grk, M.; Maksimović, N.; Damnjanović, T.; Novaković, I.; Kačar, K.; Pesic, M.; Perovic, D.; et al. Analysis of the association between polymorphisms within PAI-1 and ACE genes and Ischemic Stroke outcome after rt-PA therapy. J. Pharm. Pharm. Sci. 2019, 22, 142-149. [CrossRef] [PubMed]

82. Yi, X.; Lin, J.; Wang, Y.; Zhou, Q.; Wang, C.; Cheng, W.; Chi, L. Association of Cytochrome P450 Genetic Variants with Clopidogrel Resistance and Outcomes in Acute Ischemic Stroke. J. Atheroscler. Thromb. 2016, 23, 1188-1200. [CrossRef]

83. Patel, S.; Arya, V.; Saraf, A.; Bhargava, M.; Agrawal, C.S. Aspirin and clopidogrel resistance in Indian patients with ischemic stroke and its associations with gene polymorphisms: A pilot study. Ann. Indian Acad. Neurol. 2019, 22, 147-152. [PubMed]

84. Falcone, G.J.; Radmanesh, F.; Brouwers, H.B.; Battey, T.W.; Devan, W.J.; Valant, V.; Raffeld, M.R.; Chitsike, L.P.; Ayres, A.M.; Schwab, K.; et al. APOE $\varepsilon$ variants increase risk of warfarin-related intracerebral hemorrhage. Neurology 2014, 83, 1139-1146. [CrossRef] [PubMed]

85. Novakovic, I.; Maksimovic, N.; Pavlovic, A.; Zarkovic, M.; Rovcanin, B.; Mirkovic, D.; Pekmezovic, T.; Cvetkovic, D. Introduction to Molecular Genetic Diagnostics. J. Med. Biochem. 2014, 33, 3-7. [CrossRef]

86. Rafiee, S.; Rajabibazl, M.; Meshkani, R.; Daraei, A.; Zargari, M.; Sharafeddin, F.; Fazeli, Z.; Milani, A.T.; Taherkhani, M. Association of Warfarin Therapy with APOE and VKORC1 Genes Polymorphism in Iranian Population. Iran. J. Pharm. Res. 2017, 16, 1230-1237. [PubMed]

87. Zeng, J.; Wang, Y.; Luo, Z.; Chang, L.C.; Yoo, S.; Yan, H.; Choi, Y.; Xie, X.; Deverman, B.E.; Gradineru, V.; et al. TRIM9-Mediated Resolution of Neuroinflammation Confers Neuroprotection upon Ischemic Stroke in Mice. Cell Rep. 2019, 27, 549-560.e6. [CrossRef]

88. Peña, I.D.; Borlongan, C.V. Translating G-CSF as an Adjunct Therapy to Stem Cell Transplantation for Stroke. Transl. Stroke Res. 2015, 6, 421-429. [CrossRef]

89. Modi, J.; Menzie-Suderam, J.; Xu, H.; Trujillo, P.; Medley, K.; Marshall, M.L.; Tao, R.; Prentice, H.; Wu, J.-Y. Mode of action of granulocyte-colony stimulating factor (G-CSF) as a novel therapy for stroke in a mouse model. J. Biomed. Sci. 2020, 27, 19. [CrossRef]

90. Balseanu, A.T.; Buga, A.M.; Catalin, B.; Wagner, D.C.; Boltze, J.; Zagrean, A.M.; Reymann, K.; Schaebitz, W.; Popa-Wagner, A. Multimodal Approaches for Regenerative Stroke Therapies: Combination of Granulocyte Colony-Stimulating Factor with Bone Marrow Mesenchymal Stem Cells is Not Superior to G-CSF Alone. Front. Aging Neurosci. 2014, 6, 130. [CrossRef]

91. Buga, A.M.; Scheibe, J.; Moller, K.; Ciobanu, O.; Posel, C.; Boltze, J.; Popa-Wagner, A. Granulocyte colony-stimulating factor and bone marrow mononuclear cells for stroke treatment in the aged brain. Curr. Neurovasc. Res. 2015, 12, 155-162. [CrossRef] [PubMed]

92. Ren, J.; Chen, Y.I.; Liu, C.H.; Chen, P.-C.; Prentice, H.; Wu, J.-Y.; Liu, P.K. Noninvasive tracking of gene transcript and neuroprotection after gene therapy. Gene Ther. 2016, 23, 1-9. [CrossRef] [PubMed]

93. Chen, M.; Geoffroy, C.G.; Meves, J.M.; Narang, A.; Li, Y.; Nguyen, M.T.; Khai, V.S.; Kong, X.; Steinke, C.L.; Carolino, K.I.; et al. Leucine Zipper-Bearing Kinase Is a Critical Regulator of Astrocyte Reactivity in the Adult Mammalian CNS. Cell Rep. 2018, 22, 3587-3597. [CrossRef] [PubMed] 
94. Sokolov, M.E.; Bashirov, F.V.; Markosyan, V.A.; Povysheva, T.V.; Fadeev, F.O.; Izmailov, A.A.; Kuztetsov, M.S.; Safiullov, Z.Z.; Shmarov, M.M.; Naroditskyi, B.S.; et al. Triple-gene therapy for stroke: A proof-of-concept in vivo study in rats. Front. Pharmacol. 2018, 9, 111. [CrossRef]

95. Chen, Y.C.; Ma, N.X.; Pei, Z.F.; Wu, Z.; Do-Monte, F.H.; Keefe, S.; Yellin, E.; Chen, M.S.; Yin, J.C.; Lee, G.; et al. NeuroD1 AAV-Based Gene Therapy for Functional Brain Repair after Ischemic Injury through In Vivo Astrocyte-to-Neuron Conversion. Mol. Ther. 2020, 28, 217-234. [CrossRef]

96. Ritzel, R.M.; Lai, Y.J.; Crapser, J.D.; Patel, A.R.; Schrecengost, A.; Grenier, J.M.; Mancini, N.S.; Patrizz, A.; Jellison, E.R.; Morales-Scheihing, D.; et al. Aging alters the immunological response to ischemic stroke. Acta Neuropathol. 2018, 136, 89-110. [CrossRef]

97. Manwani, B.; Liu, F.; Scranton, V.; Hammond, M.D.; Sansing, L.H.; McCullough, L.D. Differential effects of aging and sex on stroke induced inflammation across the lifespan. Exp. Neurol. 2013, 249, 120-131. [CrossRef]

98. Badan, I.; Platt, D.; Kessler, C.; Popa-Wagner, A. Temporal dynamics of degenerative and regenerative events associated with cerebral ischemia in aged rats. Gerontology 2003, 49, 356-365. [CrossRef]

99. Popa-Wagner, A.; Dinca, I.; Yalikun, S.; Walker, L.; Kroemer, H.; Kessler, C. Accelerated delimitation of the infarct zone by capillary-derived nestin-positive cells in aged rats. Curr. Neurovasc. Res. 2006, 3, 3-13. [CrossRef]

100. Shin, Y.J.; Kim, H.L.; Park, J.M.; Cho, J.M.; Kim, S.Y.; Lee, M.Y. Characterization of nestin expression and vessel association in the ischemic core following focal cerebral ischemia in rats. Cell Tissue Res. 2013, 351, 383-395. [CrossRef]

101. Ahnstedt, H.; McCullough, L.D. The impact of sex and age on T cell immunity and ischemic stroke outcomes. Cell. Immunol. 2019, 345, 103960. [CrossRef] [PubMed]

102. Buga, A.M.; Di Napoli, M.; Popa-Wagner, A. Preclinical models of stroke in aged animals with or without comorbidities: Role of neuroinflammation. Biogerontology 2013, 14, 651-662. [CrossRef] [PubMed]

103. Petcu, E.B.; Sfredel, V.; Platt, D.; Herndon, J.G.; Kessler, C.; Popa-Wagner, A. Cellular and molecular events underlying the dysregulated response of the aged brain to stroke: A mini-review. Gerontology 2008, 54, 6-17. [CrossRef] [PubMed]

(C) 2020 by the authors. Licensee MDPI, Basel, Switzerland. This article is an open access article distributed under the terms and conditions of the Creative Commons Attribution (CC BY) license (http://creativecommons.org/licenses/by/4.0/). 